\title{
Trend analysis and change point detection of annual and seasonal precipitation and temperature series over southwest Iran
}

\author{
Mohammad Zarenistanak ${ }^{1}$, Amit G Dhorde ${ }^{1, *}$ and R H Kripalani ${ }^{2}$ \\ ${ }^{1}$ Department of Geography, University of Pune, Pune 411 007, India. \\ ${ }^{2}$ Centre for Advanced Training, Indian Institute of Tropical Meteorology, Pune 411 008, India. \\ ${ }^{*}$ Corresponding author. e-mail: amitdhorde@unipune.ac.in
}

This paper presents results of trend analysis and change point detection of annual and seasonal precipitation, and mean temperature (TM), maximum temperature (TMAX) and minimum temperature (TMIN) time series of the period 1950-2007. Investigations were carried out for 50 precipitation stations and 39 temperature stations located in southwest Iran. Three statistical tests including Pettitt's test, Sequential Mann-Kendall test (SQ-MK test) and Mann-Kendall rank test (MK-test) were used for the analysis. The results obtained for precipitation series indicated that most stations showed insignificant trends in annual and seasonal series. Out of the stations which showed significant trends, highest numbers were observed during winter season while no significant trends were detected in summer precipitation. Moreover, no decreasing significant trends were detected by statistical tests in annual and seasonal precipitation series. The analysis of temperature trends revealed a significant increase during summer and spring seasons. TMAX was more stable than TMIN and TM, and winter was stable compared to summer, spring and autumn seasons. The results of change point detection indicated that most of the positive significant mutation points in TM, TMAX and TMIN began in the 1990s.

\section{Introduction}

Global climate has changed significantly in the last hundred years. Global mean surface air temperature has increased by $0.74^{\circ} \mathrm{C}$ during the last century (IPCC 2007). Increasing temperature, snow cover retreat and changing patterns of precipitation, are among the many consequences which are attributed to climate change. Trend detection in temperature and precipitation time series is one of the interesting research areas in climatology. It is noted that precipitation and temperature changes are not globally uniform. Regional variations can be much larger, and considerable spatial and temporal variations may exist between climatically different regions (Yue and Hashino 2003). In Iran, surveys of long-term temperature and precipitation variations, and trends of data continue to go unnoticed despite the fact that the region is suffering from serious environmental, agricultural and water resource issues. Iran is located in mid latitude dry zone where rain is the only assured renewable water source, and any significant trend in precipitation and temperature is important for water resource management in Iran.

Trend analysis and change point detection in temperature and precipitation series have been investigated by many researchers throughout the world (Serra et al. 2001; Turkes and Sumer 2004; Zer Lin et al. 2005; Partal and Kahya 2006;

Keywords. Climate change; temperature; precipitation; trend analysis; change point detection; southwest Iran. 
Smadi 2006; Smadi and Zghoul 2006; Al Buhairi 2010; Karpouzos et al. 2010; Sun et al. 2010; Croitoru et al. 2012). Researches on temperature and precipitation were carried out by the following Iranian scientists: Alijani (1997) investigated annual and seasonal TM using the MK-test at Tabriz, Tehran, Isfahan and Bushehr stations for the period 1951 to 1993. His results did not show any dominant and widespread climate changes, but climatic fluctuation was observed at the stations. Besides, winter temperature series were relatively stable and showed a trace of cooling trend while the other seasonal series indicated a noticeable change and the second half of the study period became warmer. Boroujerdy (2008) used Mann-Kendall test to define trend in annual and seasonal precipitation stations for the period 19602001. The results showed that the annual precipitation had a decreasing trend at stations in the west, northwest and southeast and an increasing trend at most stations in the other parts of the country. Majority of the trends indicated reduced precipitation during spring. Tabari and Hosseinzadeh Talaee (2011a) analysed temperature series from 29 stations in Iran for the period 1966-2005 using Mann-Kendall and Mann-Whitney tests. The result indicate that annual mean temperature increased at 25 out of 29 stations, of which 17 stations showed significant trends. The analysis also indicated that most of the positive significant change points began in 1972 at all stations except the coastal ones. Modarres and da Silva (2007) analyzed the time series of annual rainfall, number of rainy-days per year and monthly rainfall of 20 stations using the Mann-Kendall test to assess climate variability in the arid and semi-arid regions of Iran. Their results showed that there was no significant climate variability in the arid and semi-arid environments of Iran. Tabari and Hosseinzadeh Talaee (2011b) examined temporal trends of precipitation at 41 stations in Iran for the period 1966-2005 using the Mann-Kendall test, the Sen's slope estimator and the linear regression. They used effective sample size (ESS) method to eliminate the effect of lag-1 serial correlation in the Mann-Kendall test. The results showed a significant negative trend in annual precipitation series at seven stations. In addition, the number of significant trends in the winter series was higher than those in other seasonal series. Tabari and Hosseinzadeh Talaee (2011c) analyzed annual, seasonal, and monthly TMAX and TMIN in the western half of Iran using the MK-test, the Sen's slope estimator and the linear regression during 1966-2005. They identified a warming trend in $85 \%$ of the stations and a negative one in the remaining stations. In addition, the study showed that a large number of stations experienced significant warming trend in summer, especially in August.

Most of the Iranian scientists have focused only on single climatic parameter. In this research, more climate parameters have been considered and three statistical tests were used for trend and change point detection in order to find out climate trends in the climate of the study area. The main aim of the present study was to detect trends and change point in annual and seasonal precipitation, and TM, TMAX and TMIN series during the period 1950-2007 over southwestern Iran by using Pettitt's test, SQ-MK test and MK-test.

\section{Methodology}

\subsection{Study area and data}

The study area covers southwestern part of Iran, particularly the provinces of Isfahan, Chaharmahal and Bakhtiari, Kohgiluyeh and Boyer-Ahmad, Lorestan and Khuzestan. The region is spread over $231,547 \mathrm{~km}^{2}$, which is about $14 \%$ of the country's area and extends from $29^{\circ} 56^{\prime}$ to $31^{\circ} 9^{\prime}$ northern latitude, and $51^{\circ} 25^{\prime}$ to $55^{\circ} 33^{\prime}$ eastern longitude. From a geological point of view, this region can be divided into eastern plains, western plains, south western plains and the Zagros Mountain range. The elevation ranges from $0 \mathrm{~m}$ in the coastal areas of the Persian Gulf to over $4430 \mathrm{~m}$ in the Dena Mountain.

Observed monthly precipitation and temperature data for the period 1950 to 2007 obtained from Islamic Republic of Iran Meteorological Organization (IRIMO) and Iranian Water Resources Management Organization were considered for statistical analysis. Spatial distribution of 50 precipitation stations and 39 temperature stations is illustrated in figure 1 and data available is presented in table 1 .

Monthly data obtained were converted to seasonal and annual averages for each station. Seasons were defined as follows: winter (January-March), spring (April-June), summer (July-September) and autumn (October-December). The data were carefully analyzed for homogeneity and for missing data. To test homogeneity of the data standard normal homogeneity test (Alexandersson 1986) and standard normal homogeneity test by Alexandersson and Moberg (1997) were applied. The results indicated that the data are fairly homogeneous.

\subsection{Techniques used}

Three statisitcal techniques have been used in the research: Pettitt's test, SQ-MK test and MK-test. Following sections give details of these techniques. 

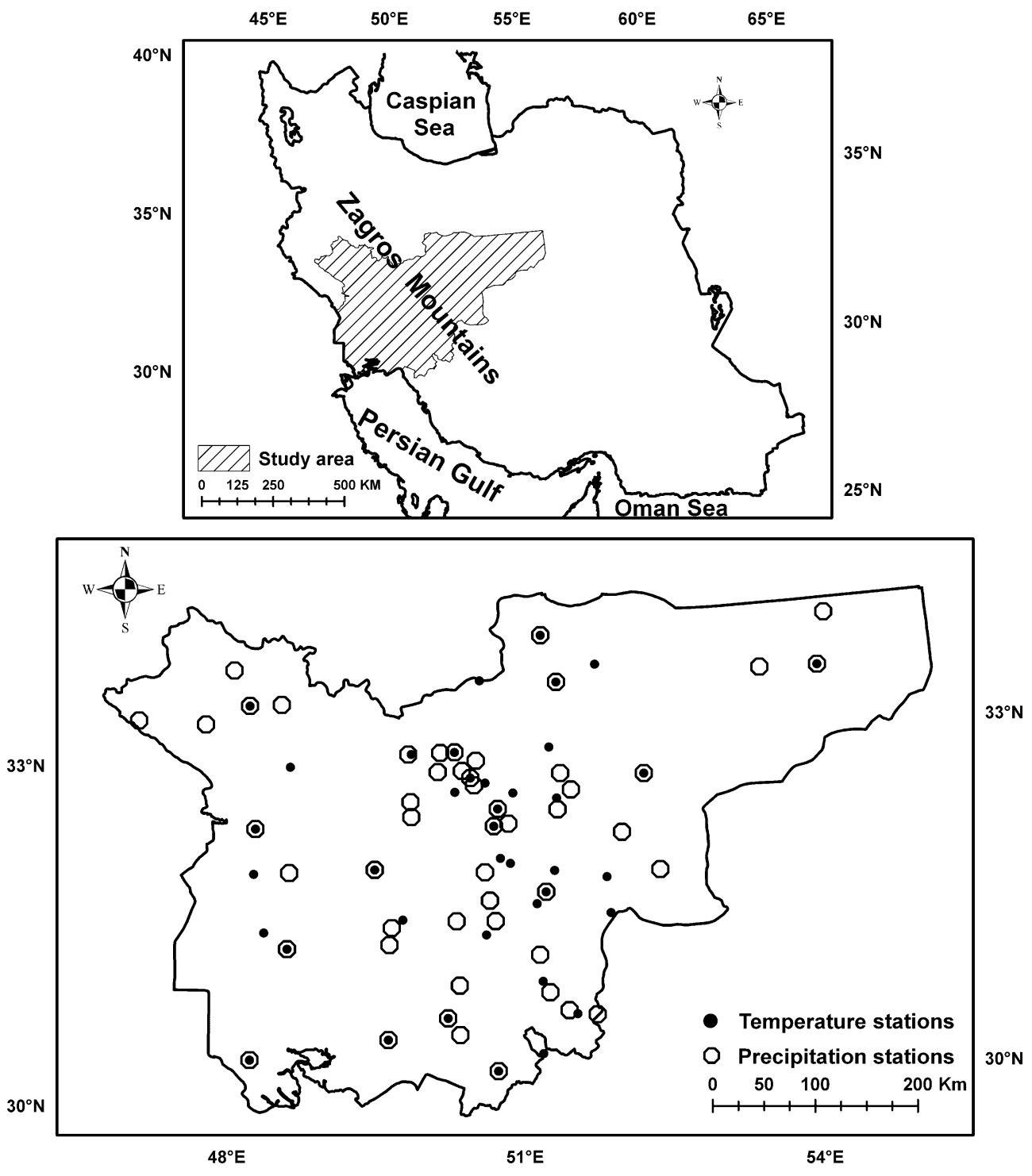

Figure 1. Location of the study area and precipitation and temperature stations.

\subsubsection{Pettitt's test}

This test, developed by Pettitt (1979) is a nonparametric test, which is useful for evaluating the occurrence of abrupt changes in climatic records (Sneyers 1990; Tarhule and Woo 1998; Smadi and Zghoul 2006). One of the reasons for using this test is that it is more sensitive to breaks in the middle of the time series (Wijngaard et al. 2003). The statistics used for the Pettitt's test has been explained by Kang and Yusof (2012); Dhorde and Zarenistanak (2013) and many others. It is computed as follows:

The first step is to compute $U_{k}$ statistic using the following formula

$$
U_{k}=2 \sum_{i=0}^{n} m_{i}-k(n+1),
$$

where $m_{i}$ is the rank of the $i$ th observation when the values $x_{1}, x_{2}, \ldots, x_{n}$ in the series are arranged in ascending order and $k$ takes values from 1 , $2, \ldots, n$. The next step is to define the statistical change point test (SCP) as follows:

$$
K=\max _{1 \leq k \leq n}\left|U_{k}\right|
$$

When $U_{k}$ attains maximum value of $K$ in a series, then a change point will occur in the series. The critical value is obtained by:

$$
K_{\alpha}=\left[-\ln \alpha\left(n^{3}+n^{2}\right) / 6\right]^{1 / 2},
$$

where $n$ is number of observations and $\alpha$ is level of significance which determines the critical value. 


\begin{tabular}{|c|c|c|c|c|c|c|c|c|c|c|c|c|c|}
\hline Station & $\begin{array}{l}\text { Latitude } \\
(\mathrm{N})\end{array}$ & $\begin{array}{l}\text { Longitude } \\
\text { (E) }\end{array}$ & $\begin{array}{l}\text { Altitude } \\
(\mathrm{m})\end{array}$ & $\begin{array}{l}\text { Length of } \\
\text { recorded } \\
\text { period }\end{array}$ & $\mathrm{T}$ & $\mathrm{P}$ & Station & $\begin{array}{l}\text { Latitude } \\
\qquad(\mathrm{N})\end{array}$ & $\begin{array}{l}\text { Longitude } \\
\text { (E) }\end{array}$ & $\begin{array}{l}\text { Altitude } \\
(\mathrm{m})\end{array}$ & $\begin{array}{l}\text { Length of } \\
\text { recorded } \\
\text { period }\end{array}$ & $\mathrm{T}$ & $\mathrm{P}$ \\
\hline Ab Shirin & $30^{\circ} 51^{\prime}$ & $50^{\circ} 40^{\prime}$ & 380 & 39 & - & $*$ & Kelishadorokh & $32^{\circ} 35^{\prime}$ & $51^{\circ} 00^{\prime}$ & 2050 & 41 & - & $*$ \\
\hline Abadan & $30^{\circ} 36^{\prime}$ & $48^{\circ} 25^{\prime}$ & 6 & 56 & $*$ & $*$ & Kesht Karoon & $32^{\circ} 00^{\prime}$ & $48^{\circ} 71^{\prime}$ & 59 & 31 & - & * \\
\hline Abyaneh & $33^{\circ} 56^{\prime}$ & $51^{\circ} 58^{\prime}$ & 2234 & 29 & $*$ & $*$ & Keta & $31^{\circ} 18^{\prime}$ & $51^{\circ} 25^{\prime}$ & 1600 & 34 & - & $*$ \\
\hline Adl Dozak & $32^{\circ} 00^{\prime}$ & $51^{\circ} 00^{\prime}$ & 2280 & 34 & $*$ & - & Khorramabad & $33^{\circ} 48^{\prime}$ & $48^{\circ} 36^{\prime}$ & 1125 & 56 & $*$ & $*$ \\
\hline Agh Mal & $32^{\circ} 58^{\prime}$ & $50^{\circ} 00^{\prime}$ & 1100 & 30 & - & $*$ & Kooh Payeh & $32^{\circ} 71^{\prime}$ & $52^{\circ} 43^{\prime}$ & 1700 & 31 & $*$ & - \\
\hline Ahwaz & $31^{\circ} 33^{\prime}$ & $48^{\circ} 66^{\prime}$ & 22 & 50 & $*$ & $*$ & Kordeolya & $32^{\circ} 91^{\prime}$ & $50^{\circ} 70^{\prime}$ & 2350 & 39 & - & $*$ \\
\hline Aminabad & $32^{\circ} 76^{\prime}$ & $51^{\circ} 56^{\prime}$ & 2050 & 30 & - & $*$ & Kouhpayehe & $32^{\circ} 71^{\prime}$ & $52^{\circ} 43^{\prime}$ & 1800 & 41 & - & $*$ \\
\hline Anarak & $33^{\circ} 56^{\prime}$ & $53^{\circ} 71^{\prime}$ & 1050 & 40 & - & $*$ & Lordegan & $31^{\circ} 50^{\prime}$ & $50^{\circ} 81^{\prime}$ & 1580 & 37 & - & $*$ \\
\hline Armand & $31^{\circ} 68^{\prime}$ & $50^{\circ} 76^{\prime}$ & 1050 & 36 & - & $*$ & Machin & $31^{\circ} 38^{\prime}$ & $50^{\circ} 71^{\prime}$ & 380 & 28 & $*$ & - \\
\hline Aznaveleh & $33^{\circ} 00^{\prime}$ & $50^{\circ} 00^{\prime}$ & 2400 & 41 & - & $*$ & Maghsoud Baeyk & $31^{\circ} 83^{\prime}$ & $51^{\circ} 98^{\prime}$ & 1980 & 38 & $*$ & - \\
\hline Badijan & $33^{\circ} 00^{\prime}$ & $50^{\circ} 33^{\prime}$ & 2300 & 31 & $*$ & $*$ & Mansoorkhani & $30^{\circ} 63^{\prime}$ & $51^{\circ} 80^{\prime}$ & 2100 & 40 & - & $*$ \\
\hline Bagh Malek & $31^{\circ} 55^{\prime}$ & $49^{\circ} 86^{\prime}$ & 675 & 30 & $*$ & - & Morcheh Khort & $33^{\circ} 00^{\prime}$ & $51^{\circ} 46^{\prime}$ & 1700 & 35 & $*$ & - \\
\hline Barez & $31^{\circ} 51^{\prime}$ & $50^{\circ} 41^{\prime}$ & 825 & 35 & - & $*$ & Mouteh & $33^{\circ} 61^{\prime}$ & $50^{\circ} 78^{\prime}$ & 1800 & 30 & $*$ & - \\
\hline Batari & $30^{\circ} 85^{\prime}$ & $51^{\circ} 33^{\prime}$ & 1520 & 39 & - & $*$ & Naghan & $31^{\circ} 93^{\prime}$ & $50^{\circ} 73^{\prime}$ & 2400 & 41 & - & $*$ \\
\hline Behbahan & $30^{\circ} 66^{\prime}$ & $50^{\circ} 28^{\prime}$ & 333 & 39 & - & $*$ & Neyestanak & $33^{\circ} 55^{\prime}$ & $54^{\circ} 31^{\prime}$ & 1000 & 40 & $*$ & $*$ \\
\hline Bi bi jan Abbad & $30^{\circ} 18^{\prime}$ & $50^{\circ} 76^{\prime}$ & 400 & 40 & $*$ & $*$ & Pang Tang & $32^{\circ} 93^{\prime}$ & $48^{\circ} 76^{\prime}$ & 540 & 31 & $*$ & - \\
\hline Chelgard & $32^{\circ} 45^{\prime}$ & $50^{\circ} 00^{\prime}$ & 2400 & 39 & - & $*$ & Pataweh & $30^{\circ} 95^{\prime}$ & $51^{\circ} 26^{\prime}$ & 1540 & 28 & $*$ & - \\
\hline Deh e Sadat & $31^{\circ} 48^{\prime}$ & $49^{\circ} 75^{\prime}$ & 450 & 30 & - & $*$ & Peykan & $32^{\circ} 21^{\prime}$ & $52^{\circ} 16^{\prime}$ & 1300 & 41 & - & * \\
\hline Deh Molla & $30^{\circ} 50^{\prime}$ & $49^{\circ} 66^{\prime}$ & 32 & 40 & $*$ & $*$ & Pol Zamankhan & $32^{\circ} 48^{\prime}$ & $50^{\circ} 90^{\prime}$ & 1810 & 43 & $*$ & $*$ \\
\hline Dezful & $32^{\circ} 40^{\prime}$ & $48^{\circ} 38^{\prime}$ & 143 & 46 & $*$ & $*$ & Razveh & $32^{\circ} 83^{\prime}$ & $50^{\circ} 55^{\prime}$ & 2200 & 31 & - & $*$ \\
\hline Eizad Khast & $31^{\circ} 51^{\prime}$ & $52^{\circ} 00^{\prime}$ & 2170 & 30 & $*$ & - & Sad Zayandeh Rood & $32^{\circ} 71^{\prime}$ & $50^{\circ} 78^{\prime}$ & 1990 & 39 & $*$ & - \\
\hline Emam Gheis & $31^{\circ} 73^{\prime}$ & $51^{\circ} 35^{\prime}$ & 2195 & 43 & $*$ & $*$ & Sad e Abasspour & $32^{\circ} 00^{\prime}$ & $49^{\circ} 60^{\prime}$ & 820 & 37 & $*$ & $*$ \\
\hline Endack & $30^{\circ} 95^{\prime}$ & $50^{\circ} 41^{\prime}$ & 560 & 37 & - & $*$ & Sad e Behbahan & $30^{\circ} 66^{\prime}$ & $50^{\circ} 28^{\prime}$ & 333 & 39 & $*$ & - \\
\hline Faridan Chadegan & $32^{\circ} 76^{\prime}$ & $50^{\circ} 63^{\prime}$ & 2100 & 31 & $*$ & $*$ & Sarab Handeh & $32^{\circ} 05^{\prime}$ & $50^{\circ} 90^{\prime}$ & 1880 & 38 & $*$ & - \\
\hline Faridan Damaneh & $33^{\circ} 00^{\prime}$ & $50^{\circ} 48^{\prime}$ & 2300 & 42 & $*$ & $*$ & Sarabe Seyed Ali & $33^{\circ} 80^{\prime}$ & $48^{\circ} 21^{\prime}$ & 1520 & 40 & - & $*$ \\
\hline Ghaleh Shahrookh & $32^{\circ} 65^{\prime}$ & $50^{\circ} 46^{\prime}$ & 2100 & 32 & $*$ & - & Shah Mokhtar & $30^{\circ} 68^{\prime}$ & $51^{\circ} 51^{\prime}$ & 1730 & 39 & - & * \\
\hline Haft Tapeh & $32^{\circ} 00^{\prime}$ & $48^{\circ} 35^{\prime}$ & 63 & 43 & $*$ & - & Shahre Kord & $32^{\circ} 33^{\prime}$ & $50^{\circ} 85^{\prime}$ & 2061 & 51 & $*$ & $*$ \\
\hline Hamgin & $31^{\circ} 91^{\prime}$ & $51^{\circ} 45^{\prime}$ & 2150 & 43 & $*$ & - & Solgaun & $31^{\circ} 63^{\prime}$ & $51^{\circ} 25^{\prime}$ & 2150 & 26 & $*$ & - \\
\hline Hamidiyeh & $31^{\circ} 48^{\prime}$ & $48^{\circ} 43^{\prime}$ & 21 & 43 & $*$ & - & $\mathrm{Tad}$ & $32^{\circ} 45^{\prime}$ & $51^{\circ} 51^{\prime}$ & 1700 & 41 & - & $*$ \\
\hline Isfahan & $32^{\circ} 61^{\prime}$ & $51^{\circ} 06^{\prime}$ & 1550 & 56 & $*$ & $*$ & Tangeh Berim & $30^{\circ} 31^{\prime}$ & $51^{\circ} 23^{\prime}$ & 750 & 38 & $*$ & - \\
\hline Jandagh & $34^{\circ} 00^{\prime}$ & $54^{\circ} 43^{\prime}$ & 1200 & 43 & - & $*$ & Tangeh Seayab & $33^{\circ} 38^{\prime}$ & $47^{\circ} 20^{\prime}$ & 880 & 36 & - & * \\
\hline Jangalbani Badroud & $33^{\circ} 70^{\prime}$ & $52^{\circ} 00^{\prime}$ & 1056 & 33 & $*$ & - & Yanchesh & $32^{\circ} 70^{\prime}$ & $50^{\circ} 66^{\prime}$ & 2100 & 31 & - & * \\
\hline Jo Kang & $31^{\circ} 33^{\prime}$ & $49^{\circ} 71^{\prime}$ & 330 & 40 & - & $*$ & Yasuj & $30^{\circ} 65^{\prime}$ & $51^{\circ} 60^{\prime}$ & 1821 & 34 & $*$ & $*$ \\
\hline Kalbal & $32^{\circ} 83^{\prime}$ & $50^{\circ} 30^{\prime}$ & 2290 & 31 & - & $*$ & Zaghehe & $33^{\circ} 48^{\prime}$ & $48^{\circ} 70^{\prime}$ & 2000 & 49 & - & $*$ \\
\hline Kashan & $33^{\circ} 98^{\prime}$ & $51^{\circ} 45^{\prime}$ & 982 & 40 & $*$ & $*$ & Zefreh Flawarjan & $32^{\circ} 55^{\prime}$ & $51^{\circ} 51^{\prime}$ & 1605 & 40 & $*$ & - \\
\hline Kashkan Afrineh & $33^{\circ} 33^{\prime}$ & $47^{\circ} 90^{\prime}$ & 820 & 40 & - & $*$ & - & - & - & - & - & - & - \\
\hline
\end{tabular}




\subsubsection{Sequential Mann-Kendall test}

The SQ-MK test proposed by Sneyers (1990) is used for determining the approximate year of the beginning of a significant trend ( $\mathrm{Lu}$ et al. 2004; Partal and Kahya 2006; Tabari et al. 2011; Shifteh Some/e et al. 2012). This test sets up two series, a progressive one $u(t)$ and a backward one $u^{\prime}(t)$. If they cross each other and diverge beyond the specific threshold value, then there is a statistically significant trend. The point where they cross each other indicates the approximate year at which the trend begins (Mosmann et al. 2004). Herein, $u(t)$ is a standardized variable that has zero mean and unit standard deviation. Therefore, its sequential behaviour fluctuates around the zero level. $u(t)$ is the same as the $z$ values that are found from the first to last data point. This test considers the relative values of all terms in the time series $\left(x_{1}, x_{2}, \ldots\right.$, $\left.x_{n}\right)$. Following steps are applied in sequence:

I. The magnitudes of $x_{j}$ annual mean time series $(j=1, \ldots, n)$ are compared with $x_{k},(k=1, \ldots$, $j-1)$. At each comparison, the number of cases $x_{j}>x_{k}$ is counted and denoted by $n_{j}$.

II. The test statistic $t$ is then given by equation:

$$
t_{j}=\sum_{1}^{j} n_{j}
$$

III. The mean and variance of the statistic are:

$$
e(t)=\frac{n(n-1)}{4}
$$

and

$$
\operatorname{var} t_{j}=\frac{j(j-1)(2 j+5)}{72}
$$

IV. The sequential values of statistic $u$ are then calculated as:

$$
u(t)=\frac{t_{j}-e_{(t)}}{\sqrt{\operatorname{var}\left(t_{j}\right)}} .
$$

Similarly, the values of $u^{\prime}(t)$ are computed backward, starting from the end of series. The sequential version of the Mann-Kendall test could be considered as an effective way of locating the beginning year of a trend. The intersection of the curves showing the forward $(u)$ and back-ward $\left(u^{\prime}\right)$ represents the time when a trend or change starts. Critical value for $95 \%$ confidence level is \pm 1.96 .

\subsubsection{Mann-Kendall rank test}

The MK-test is a non-parametric test used to detect significant trends in hydrological and meteorological time series (Gadgil and Dhorde 2005;
Modarres and da Silva 2007; Tabari et al. 2011). In this test we have to use only the relative values of all terms in the series $X_{i}$. Therefore, the first step is to replace the $X_{i}$ values by their ranks $k_{i}$, such that each value is assigned a number ranging from 1 to $N$.

The second step consists of computing the statistic $P$. This includes the following procedure: Compare the rank $\left(k_{1}\right)$ of the first value with those of the later values from the second to the $N$ th value. Count the number of later values whose rank exceeds $k_{i}$, and denote this number by $n_{1}$. Then compare the rank of the second value $\left(k_{2}\right)$ with those of the later values, count the number of later values that exceed $k_{2}$ and denote this by $n_{2}$. Continue this procedure for each value of the series ending with $k_{N-1}$ and its corresponding number $n_{N-1}$. Now $P$ can be computed as follows:

$$
P=\sum_{i=1}^{N-1} n_{i}
$$

The next step involves computation of the statistic $\tau$ by using the following equation

$$
\tau=\frac{4 P}{N(N-1)}-1
$$

This gives us $\tau$ of Mann-Kendall test.

The value of ' $\tau$ ' can thus be used as the basis of a significance test by comparing it with

$$
(\tau)_{t}=0 \pm t_{g} \sqrt{\frac{4 N+10}{9 N(N-1)}},
$$

where $t_{g}$ is the desired probability point of the Gaussian normal distribution. In the present study, $t_{g}$ at 0.05 point has been taken for comparison.

The results obtained by all these tests were tested at $95 \%$ confidence level.

\section{Results and discussion}

Based on the Pettitt's test and SQ-MK test the change point detection for annual and seasonal precipitation and TM, TMAX and TMIN series were applied to identify the junction of the curves, and therefore, to detect the beginning year of the trend. The most important reason for mutation point in precipitation and temperature series, include station relocation, change in instruments, changes in observation time and methods for calculation of mean and climate changes and changes in atmospheric circulation (Smadi 2006). The MK-test was applied to detect monotonous trends in annual and seasonal precipitation and TM, TMAX and TMIN series. 


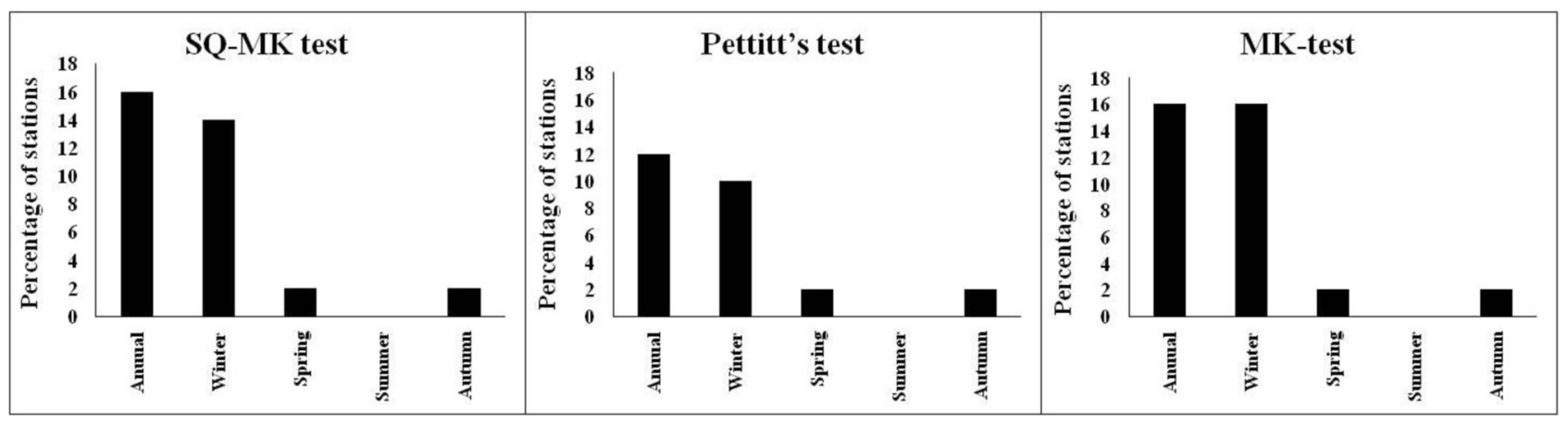

Figure 2. Percentage of stations with significant trends at 95\% confidence level by the MK-test, Pettitt's test and SQ-MK test for annual and seasonal precipitation series.

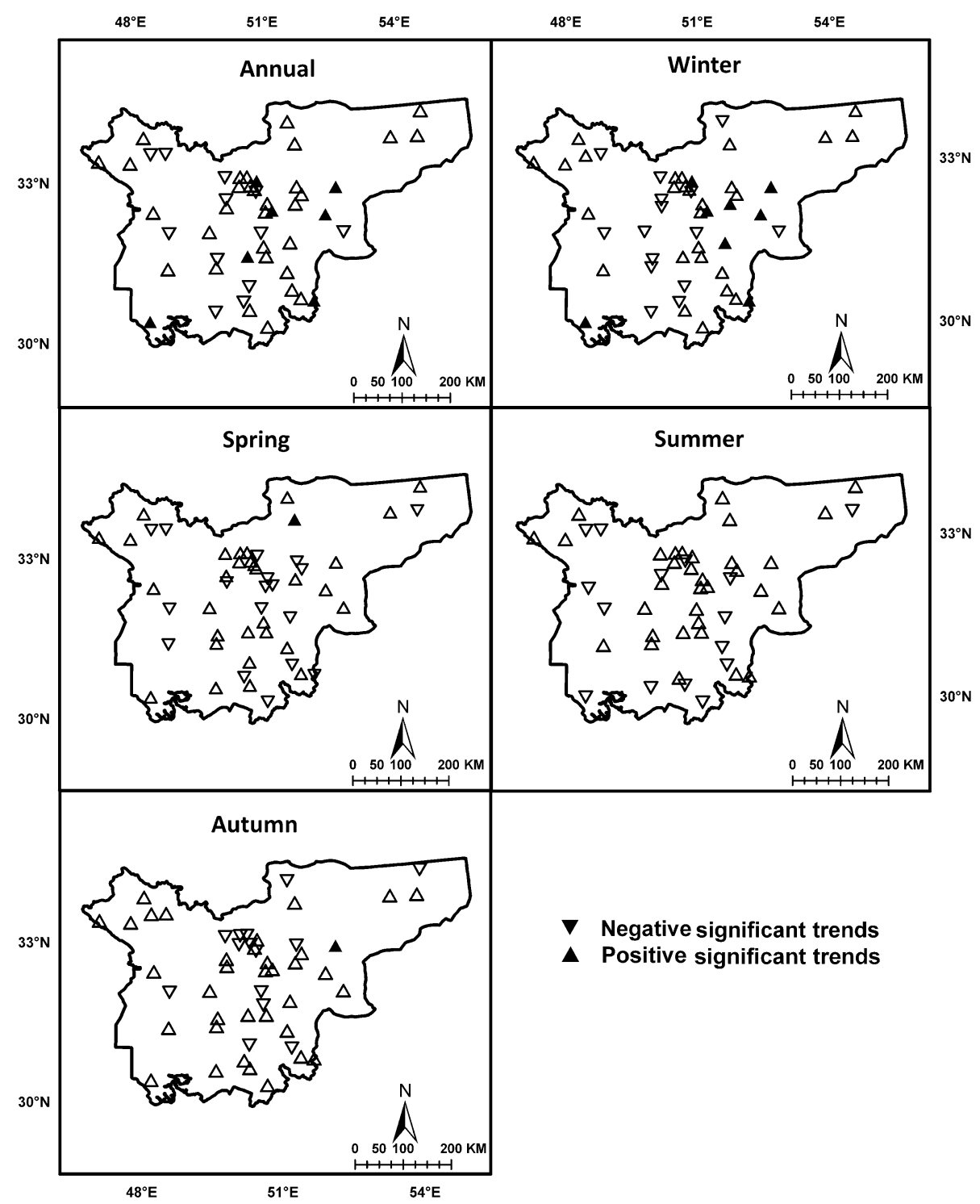

Figure 3. Spatial distribution of trends in annual and seasonal precipitation series obtained by MK-test. Shaded triangles indicate trends significant at $95 \%$ confidence level. Hollow triangles indicate insignificant trends.

Most of the Iranian scientists such as Boroujerdy (2008), Ghahraman and Taghvaeian (2008), Katiraie et al. (2007), Roshan et al. (2011),
Sabohi 2009), and Shirgholami and Ghahraman (2009) analyzed trends in precipitation and temperature series for the whole of Iran. However, 
in the present study, trend analyses and change point detection at 50 precipitation stations and 39 temperature stations over southwestern Iran are studied which would be beneficial for knowing details of climatic changes over a smaller region.

\subsection{Analysis of precipitation}

The results of statistical analysis at $95 \%$ confidence level for annual and seasonal precipitation data using different techniques were approximately similar. Both positive and negative trends were identified by all the tests. However, all negative trends were insignificant, and only some positive trends were significant. One of the reasons for so many insignificant trends could be non-availability of century scale data for the selected stations. Raziei (2008) also observed insignificant positive trends over southwest part of Iran. Another study by Shifteh Somere et al. (2012) found insignificant trends in annual precipitation series at most of the stations in Iran. In these studies also the data availability was less than 100 years.

Results of all the tests with regard to positive trends are illustrated in figure 2. The results of MK-test and SQ-MK test for annual precipitation series indicated positive significant tendencies at $16 \%$ of the stations. Results of Pettitt's test revealed existence of positive significant change point in only $12 \%$ of the time series. Spatial distribution of annual precipitation showed that positive trends occurred only at 7 stations, mostly in the central parts (5 stations) of the study area (figure 3). However, the year of mutation point (year when the trend begins) is different for each of these stations.

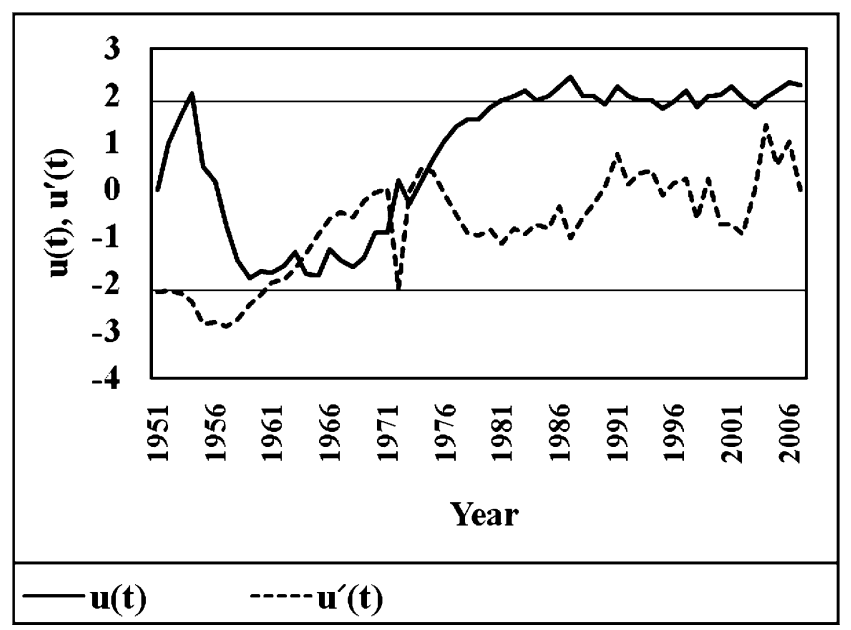

Figure 4. Graphical representation of sequential values of the statistics forward series $u(t)$ (solid line) and backward series $u^{\prime}(t)$ (dashed line) obtained by SQ-MK test for annual precipitation series observed at Abadan station.
Abadan station situated in the coastal area of Persian Gulf experienced positive trend. Mutation point at this station occurred around 1973 (figure 4). As shown in figure 2, majority of the trends in seasonal data occurred in winter. The largest contribution to annual precipitation is from winter season, and therefore, the results of statistical analysis of winter series were similar to that of annual series. Furthermore, the analysis of winter series indicated positive trends at 14\%,16\% and $10 \%$ stations by SQ-MK test, MK-test and Pettitt's test, respectively. During spring and autumn seasons significant upward trend was detected only at one station, whereas during summer season no significant trend was detected.

\subsection{Analysis of temperature}

\subsubsection{Annual temperature}

The Pettitt's test, SQ-MK test and MK-test were applied to detect annual trends in TM, TMAX and TMIN series. Besides indicating tendencies, the Pettitt's test and SQ-MK test also reveal the year when the trend begins (mutation point). Outputs of these three statistical techniques for annual and seasonal TM, TMAX and TMIN series are almost similar, which is illustrated in figure 5. It was observed that $58 \%, 51 \%$ and $56 \%$ stations were dominated by increasing trend in annual TM as per Pettitt's test, SQ-MK test, and MK-test, respectively. Out of the total observed significant positive trends in annual TM by Pettitt's test $65 \%$ of mutation points began in 1990 s, whereas the SQ-MK test revealed that 90\% mutation points began in 1990s (table 2). On the other hand, negative trends in annual TM were detected only at $10 \%$ of the stations. Majority of the stations indicated warming trends for annual TMAX but the number of significant changes were less compared to annual TMIN. $41 \%, 33 \%$ and $35 \%$ stations indicated an upward trend in annual TMAX according to the Pettitt's test, SQ-MK test and MK-test, respectively. $85 \%$ positive significant mutation points in annual TMAX series occurred in 1990s, according to the Pettitt's test as well as SQ-MK test. The analysis of annual TMIN series by all the tests revealed warming tendencies at $47 \%$ of stations. Out of these stations, 47\% (by Pettitt's test) and $67 \%$ (by SQ-MK test) positive significant mutation points began in 1990s. A general warming pattern was observed over Persian Gulf coast and Zagros Mountains in annual TM, TMAX and TMIN. Figure 6 presents the spatial pattern of trends obtained by applying MK-test to annual TM, TMAX and TMIN series. Majority 


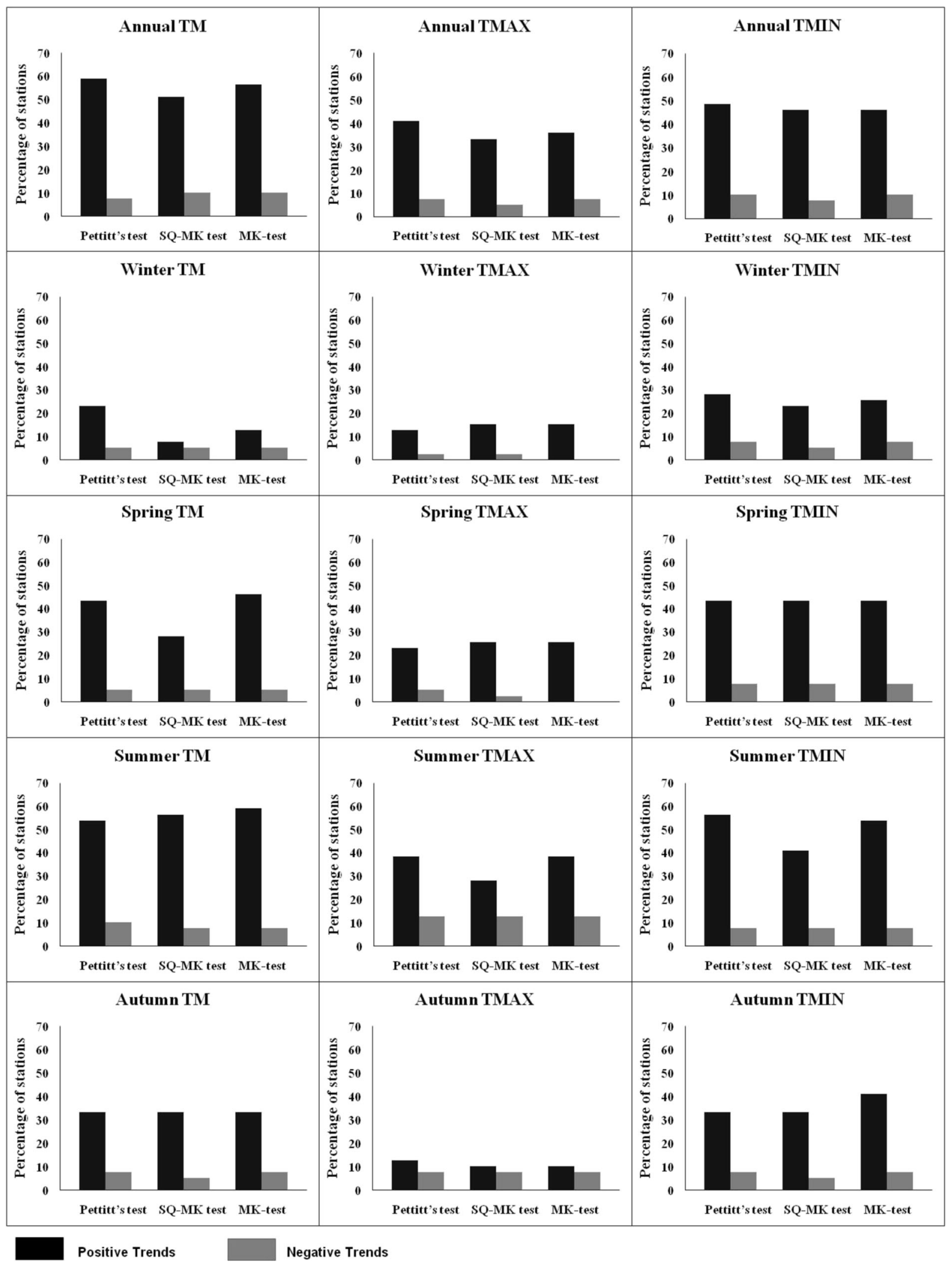

Figure 5. The percentage of stations with significant trends and change points detected at $95 \%$ confidence level by the MK-test, Pettitt's test and SQ-MK test for annual and seasonal temperature series.

of the positive significant trends are observed in the eastern half of the study area. The positive trends detected in annual series are in good agreement with the results of Tabari et al. (2011) who found a warming trend in annual TM, TMAX and TMIN series in about $69 \%, 23 \%$ and $64 \%$ of 
Table 2. Percentage of stations (out of number of stations registering positive trends) recording significant mutation points in different decades.

\begin{tabular}{|c|c|c|}
\hline & Pettitt's test & SQ-MK test \\
\hline \multicolumn{3}{|c|}{ Annual } \\
\hline \multicolumn{3}{|l|}{ TM } \\
\hline $1990 \mathrm{~s}$ & 65.21 & 90 \\
\hline $1980 \mathrm{~s}$ & 30.43 & 5 \\
\hline $1970 \mathrm{~s}$ & 4.34 & 5 \\
\hline \multicolumn{3}{|c|}{ TMAX } \\
\hline $1990 \mathrm{~s}$ & 82.35 & 84.61 \\
\hline $1980 \mathrm{~s}$ & 17.64 & 15.38 \\
\hline $1970 \mathrm{~s}$ & 0 & 0 \\
\hline \multicolumn{3}{|l|}{ TMIN } \\
\hline $1990 \mathrm{~s}$ & 47.36 & 66.66 \\
\hline $1980 \mathrm{~s}$ & 42.10 & 11.11 \\
\hline $1970 \mathrm{~s}$ & 10.52 & 22.22 \\
\hline \multicolumn{3}{|c|}{ Autumn } \\
\hline \multicolumn{3}{|l|}{ TM } \\
\hline $1990 \mathrm{~s}$ & 0 & 75 \\
\hline $1980 \mathrm{~s}$ & 84.61 & 25 \\
\hline $1970 \mathrm{~s}$ & 15.38 & 0 \\
\hline \multicolumn{3}{|c|}{ TMAX } \\
\hline $1990 \mathrm{~s}$ & 20 & 80 \\
\hline $1980 \mathrm{~s}$ & 80 & 20 \\
\hline $1970 \mathrm{~s}$ & 0 & 0 \\
\hline \multicolumn{3}{|l|}{ TMIN } \\
\hline $1990 \mathrm{~s}$ & 41 & 76.92 \\
\hline $1980 \mathrm{~s}$ & 50.66 & 15.38 \\
\hline $1970 \mathrm{~s}$ & 8.33 & 7.69 \\
\hline \multicolumn{3}{|c|}{ Spring } \\
\hline \multicolumn{3}{|l|}{ TM } \\
\hline $1990 \mathrm{~s}$ & 70.58 & 81.81 \\
\hline $1980 \mathrm{~s}$ & 11.76 & 9.09 \\
\hline $1970 \mathrm{~s}$ & 17.64 & 9.09 \\
\hline \multicolumn{3}{|c|}{ TMAX } \\
\hline $1990 \mathrm{~s}$ & 37.5 & 90 \\
\hline $1980 \mathrm{~s}$ & 50 & 10 \\
\hline $1970 \mathrm{~s}$ & 12.5 & 0 \\
\hline \multicolumn{3}{|l|}{ TMIN } \\
\hline $1990 \mathrm{~s}$ & 62.5 & 82.35 \\
\hline $1980 \mathrm{~s}$ & 31.25 & 11.76 \\
\hline $1970 \mathrm{~s}$ & 6.25 & 5.88 \\
\hline \multicolumn{3}{|c|}{ Summer } \\
\hline \multicolumn{3}{|l|}{ TM } \\
\hline $1990 \mathrm{~s}$ & 47.61 & 61.90 \\
\hline $1980 \mathrm{~s}$ & 52.38 & 38.09 \\
\hline $1970 \mathrm{~s}$ & 0 & 0 \\
\hline \multicolumn{3}{|c|}{ TMAX } \\
\hline $1990 \mathrm{~s}$ & 35.71 & 80 \\
\hline $1980 \mathrm{~s}$ & 64.28 & 20 \\
\hline $1970 \mathrm{~s}$ & 0 & 0 \\
\hline \multicolumn{3}{|l|}{ TMIN } \\
\hline $1990 \mathrm{~s}$ & 45.45 & 75 \\
\hline
\end{tabular}

Table 2. (Continued.)

\begin{tabular}{lcc}
\hline & Pettitt's test & SQ-MK test \\
\hline $1980 \mathrm{~s}$ & 54.54 & 25 \\
$1970 \mathrm{~s}$ & 4.54 & 0 \\
Winter & & \\
TM & & \\
$1990 \mathrm{~s}$ & 100 & 100 \\
$1980 \mathrm{~s}$ & 0 & 0 \\
$1970 \mathrm{~s}$ & 0 & 0 \\
TMAX & & \\
$1990 \mathrm{~s}$ & 100 & 100 \\
$1980 \mathrm{~s}$ & 0 & 0 \\
$1970 \mathrm{~s}$ & 0 & 0 \\
TMIN & & \\
$1990 \mathrm{~s}$ & 66.66 & 0 \\
$1980 \mathrm{~s}$ & 16.66 & 22.22 \\
$1970 \mathrm{~s}$ & 16.66 & - \\
\hline & - &
\end{tabular}

the stations, respectively in the western half of Iran. Another study by Tabari and Hosseinzadeh Talaee (2011c) indicated positive (negative) trends in TMAX and TMIN series at $85 \%$ (15\%) stations located in western half of Iran. Strong upward trends dominated the stations which are rapidly urbanizing or have already urbanized in the study area such as Abadan, Ahwaz, Dezful, Isfahan, Kashan and Shahre Kord, etc. The population density in these cities is very high. The cities are able to absorb more solar radiation because of high-rise buildings. Effect of the regional air pollution, which results because of consuming huge oil resources (fossil fuels) and urbanization, are affecting the climate of these cities. Besides these factors, local topography and atmospheric circulation features increase the possibility of influencing nature and magnitude of the TMAX and TMIN trends (Dhorde et al. 2009; Tabari and Hosseinzadeh Talaee 2011d).

Graphical representations of the results obtained by applying SQ-MK test to annual TM, TMAX and TMIN series are shown in figures 7-9. These figures show some examples of warming trends observed in annual TM, TMAX and TMIN series. The intersection point of the curves of $u(t)$ and $u^{\prime}(t)$ values is the mutation point that indicates the year when the trend begins. Similar analysis was done for seasonal TM, TMAX and TMIN series.

\subsubsection{Seasonal temperature analysis}

On seasonal scale, about $16 \%, 14 \%$ and $25 \%$ stations showed significant warming trend in the winter TM, TMAX and TMIN, respectively (figure 5). Results of trend analysis obtained by MK-test in seasonal series are shown in figure 10 (winter and 


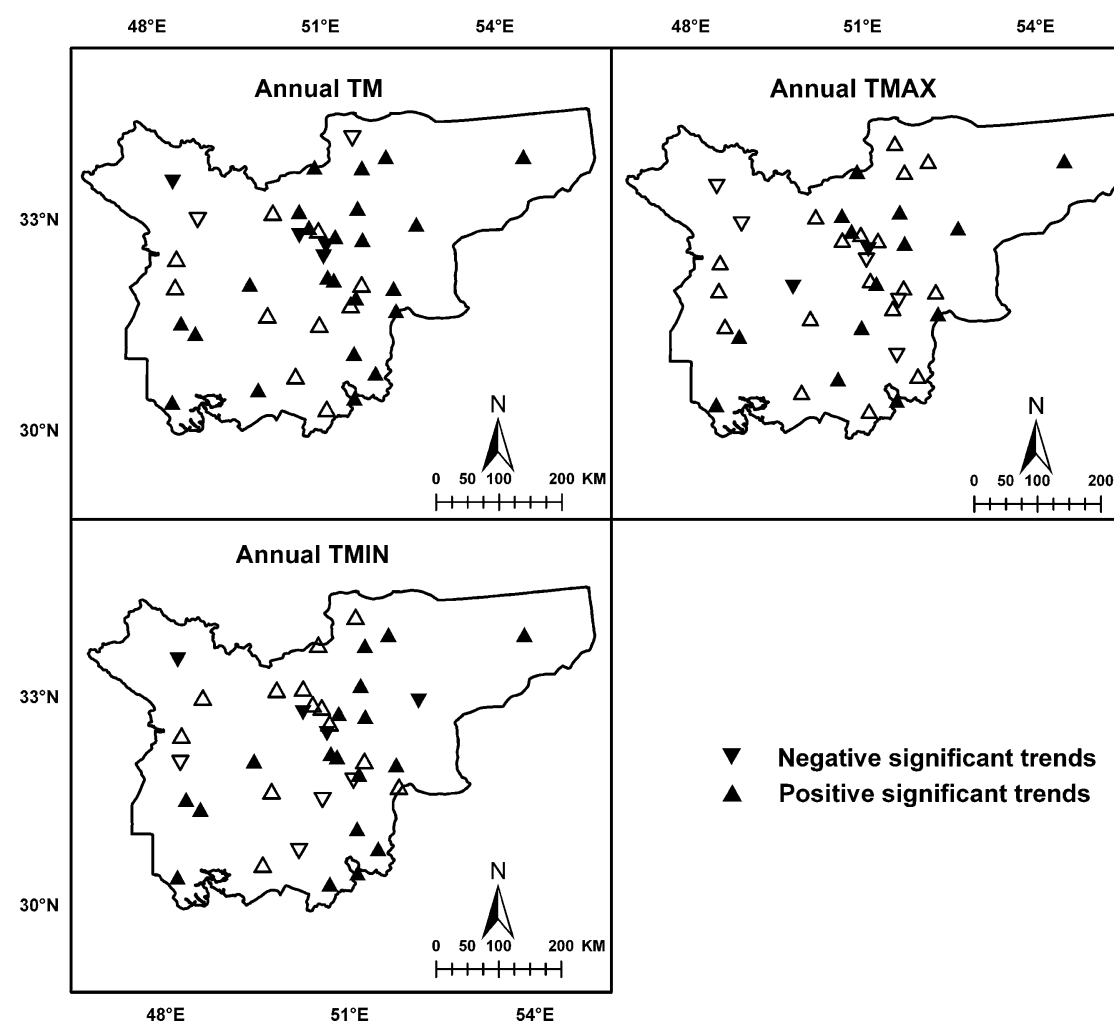

Figure 6. Result of MK-test in TM, TMAX and TMIN of annual temperature series. Significant trends at $95 \%$ confidence level are indicated by shaded triangles and hollow triangles indicate insignificant trends.

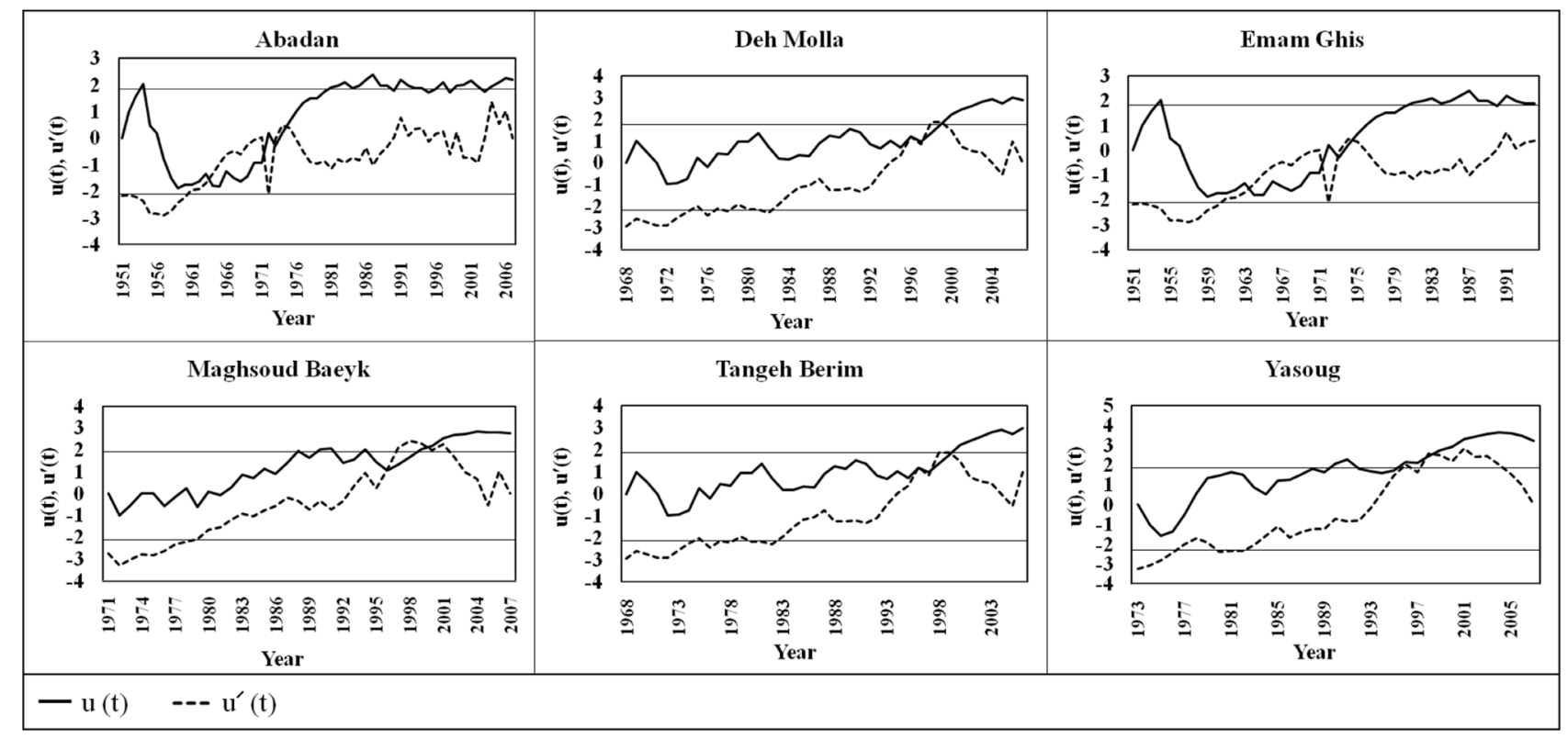

Figure 7. Sequential values of the statistics forward series $u(t)$ (solid line) and backward series $u^{\prime}(t)$ (dashed line) obtained by SQ-MK test for annual TM at some stations with the significant trends.

spring) and figure 11 (summer and autumn). Most of the stations in the Persian Gulf coastal area indicated an upward trend in TM and TMIN, but TMAX series showed a downward trend. Abadan station showed positive significant trend in TM and TMIN. A positive significant trend in TMIN was also observed at Ahwaz station. Stations from Zagros Mountains, recorded a mix of insignificant warming and cooling trends in winter TM. Sarab Handeh, Yasuj and Pang Tang stations showed 
warming trends in winter TM in the Zagros Mountains. About 4(7) stations in this area recorded significant warming trends in winter TMAX (TMIN). $100 \%$ positive significant mutation points began in the 1990s according to Pettitt's test and SQ-MK test in winter TM and TMAX series (table 2). The winter TMIN series recorded $67 \%(78 \%)$ positive significant mutation points in the 1990 s according to the Pettitt's test (SQ-MK test). Tabari et al. (2011) found that most of the positive significant mutation points began in the 1970s in Iran. However, in this research, most of the positive significant mutation points occurred in the 1990s. This also indicates that the decade of 1990 was the warmest decade of the twentieth century.

The trends during spring season indicated a general pattern of rising temperatures at some locations, though non-significant. On an average $40 \%$, $24 \%$ and $43 \%$ stations showed warming trends in the spring TM, TMAX and TMIN, respectively (figure 5). SQ-MK test showed few warming trends $(28 \%)$ in winter TM series. Most of the stations in the Persian Gulf coastal area indicated upward trends in spring TM, TMAX and TMIN, respectively (figure 10). The number of significant warming tendencies in spring TMAX was less than TM and TMIN. More than $60 \%$ positive significant mutation points in spring TM and TMIN series began in the 1990s according to the Pettitt's test and SQ-MK test (table 2). But, the analysis of TMAX series by the Pettitt's test showed that only $50 \%$ positive significant mutation points occurred between 1980 and 1990s, and by SQ-MK test $90 \%$ positive significant mutation points occurred in the 1990s.

The number of stations registering significant increase in summer TM and TMIN was more than those registering insignificant trends (figure 11). $55 \%$ and $51 \%$ stations showed warming trends in summer TM and TMAX respectively (figure 5). But, amongst the summer TMAX series, $35 \%$ stations showed warming in the study area. During this season, according to the Pettitt's test, most of the positive significant mutation points occurred between 1980 and 1990s, but according to SQ-MK test most of the positive significant mutation points began in the 1990s.

The number of significant rising tendencies in autumn was less than those observed for spring and summer, but more than in winter (figure 5). On an average $33 \%, 11 \%$ and $35 \%$ stations registered significant warming trends in autumn TM, TMAX and TMIN, respectively. During autumn, according to the Pettitt's test most of the positive significant mutation points occurred between 1980 and 1990, but SQ-MK test indicated that most of the positive significant mutation points occurred in 1990s in autumn TM series.
The results of statistical analysis of annual and seasonal TM, TMAX and TMIN series indicated more number of increasing trends in TM and TMIN. From these results, it can be inferred that, in general, the climate regime is shifting towards a regime dominated by higher temperatures. Such increasing trends in air temperature have been related to several factors, such as global warming, increased concentrations of anthropogenic green house gases, increased cloud cover, and urbanization (Smadi 2006). The positive trends in annual and seasonal TM, TMAX and TMIN found in this study are in good agreement with the results obtained by other researchers in the western regions of Iran such as Tabari et al. (2010); Tabari and Marofi (2011); Tabari and Hosseinzadeh Talaee (2011c).

\subsection{Comparison of precipitation and temperature trends}

Significant positive trends in annual precipitation series occurred only at 7 stations, out of which 5 stations were located in the central part of the study area. On the other hand annual temperature series registered higher number of stations (more than 50\%) with significantly increasing trends, though the number of temperature stations were less (39) than precipitation stations (50).

On seasonal basis majority of positive significant trends in precipitation occurred during winter season, which contributes the largest amount of precipitation to annual series. During spring and autumn seasons significant positive trend was recorded only at one station each. At seasonal level also more numbers of significant trends were observed in temperature as compared to precipitation. In the case of temperature, winter season recorded the least changes. During spring, summer and autumn seasons more stations indicated significant warming trends with larger contribution from TMIN series. During these three seasons, it was observed that significantly warming trends were concentrated in central and southern parts of the study area. But, some stations from west have registered increasing trends in spring TMAX, summer TMAX and autumn TMIN, whereas significantly increasing trends in precipitation were concentrated in the central part of the study area.

Thus two inferences can be drawn from the study. The first is that more number of stations have recorded significant increasing trends in temperature compared to precipitation. The second is that the increasing temperature trends were widespread over the study area, whereas positive significant trends in precipitation are concentrated only in the central part of the study area. 


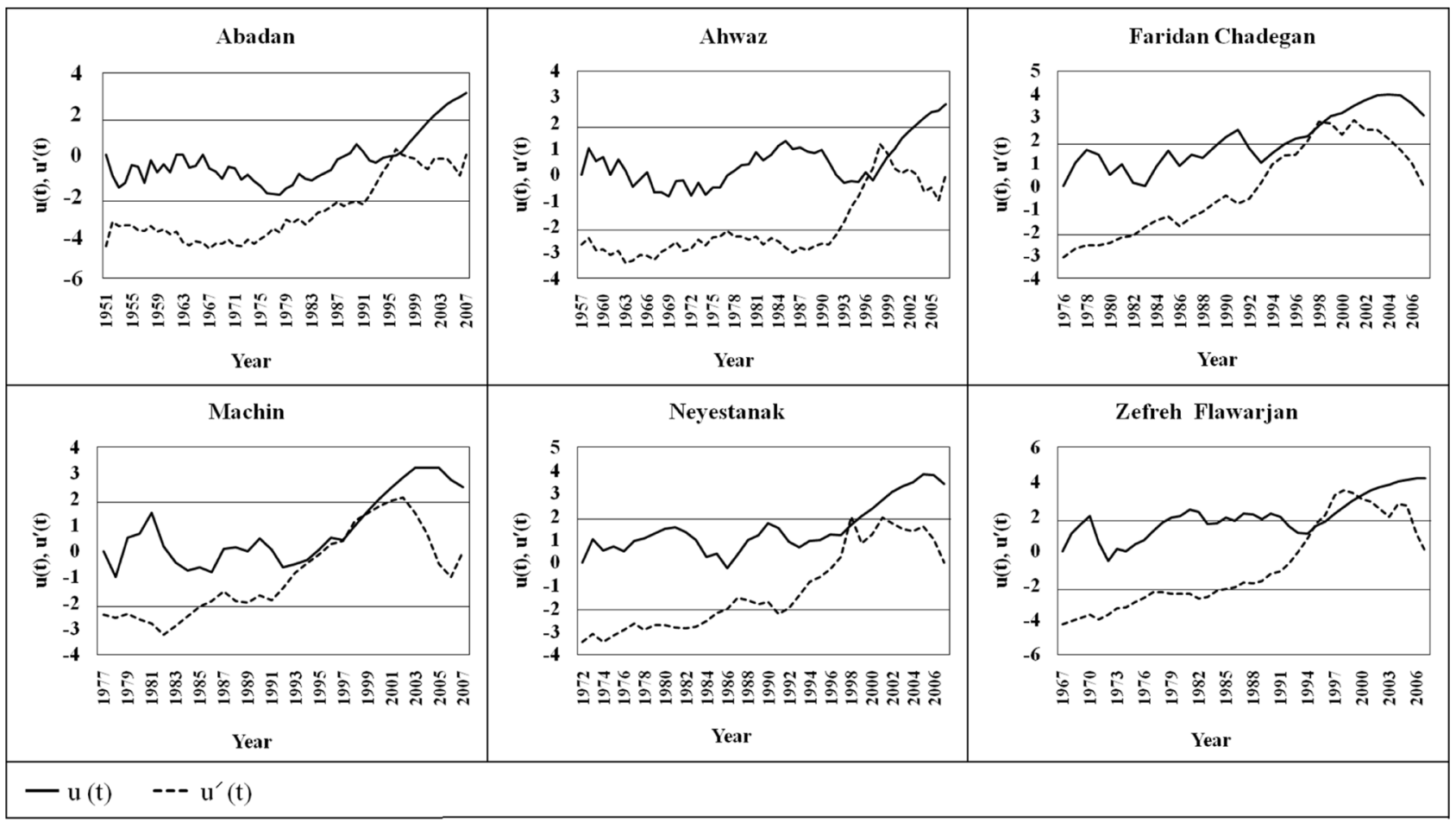

Figure 8. Sequential values of the statistics forward series $u(t)$ (solid line) and backward series $u^{\prime}(t)$ (dashed line) obtained by SQ-MK test for annual TMAX at some stations with the significant trends.

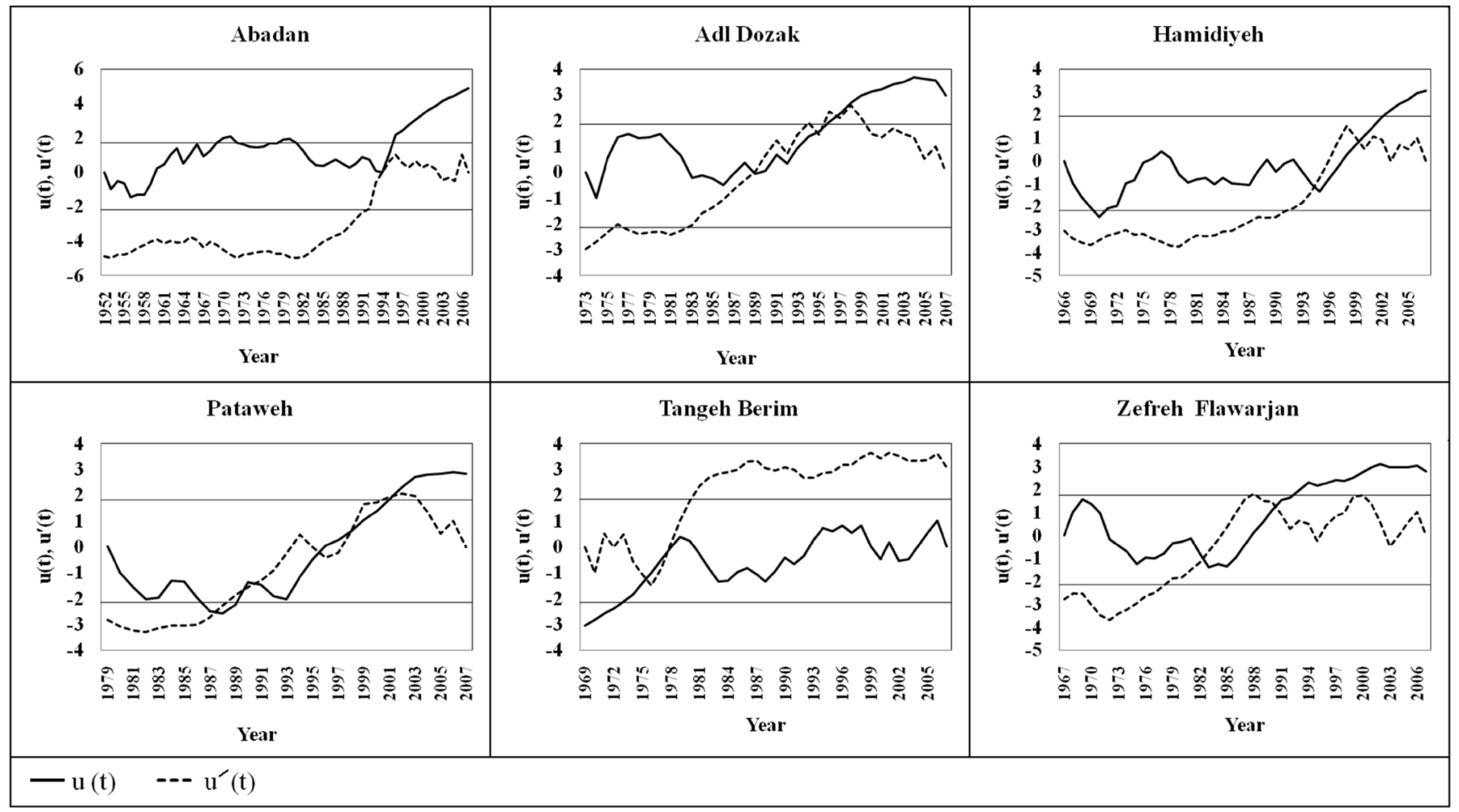

Figure 9. Sequential values of the statistics forward series $u(t)$ (solid line) and backward series $u^{\prime}(t)$ (dashed line) obtained by SQ-MK test for annual TMIN at some stations with the significant trends. 


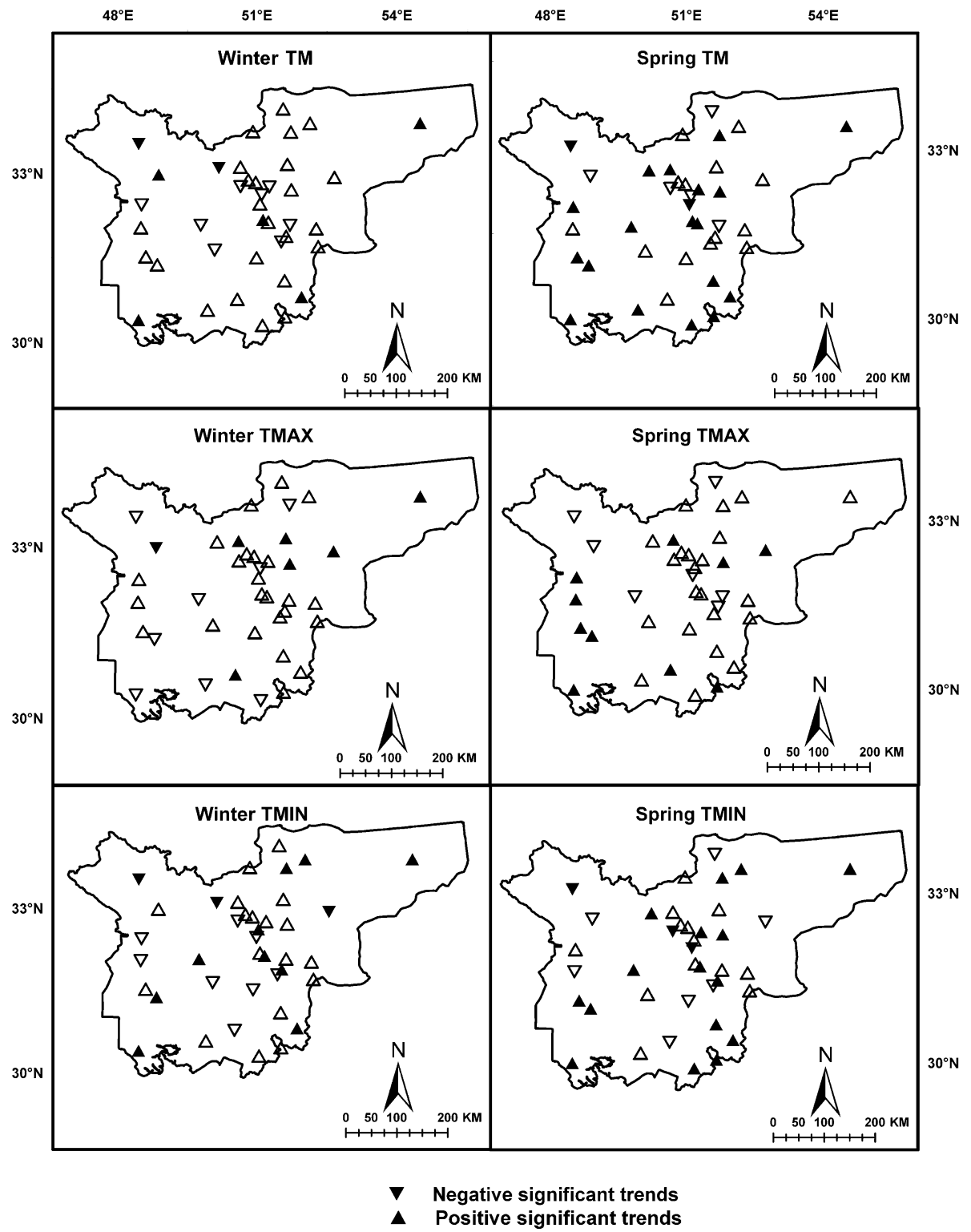

Figure 10. Trends detected by MK-test in TM, TMAX and TMIN of winter and spring series. Significant trends at $95 \%$ confidence level are indicated by shaded triangles and hollow triangles indicate insignificant trends.

\section{Conclusions}

In this study, trend analysis and change point detection of annual and seasonal precipitation, and annual and seasonal series of TM, TMAX and TMIN for the period 1950-2007 were carried out for 50 precipitation stations and 39 temperature stations located in southwest Iran. The results of the three statistical techniques that were used were found to be similar for TM, TMAX and TMIN series.

The results of trend analysis and change point detection in precipitation series are important for policy makers, water resources management and agriculture. It was observed that most of the stations showed an insignificant trend in annual and seasonal precipitation series. The highest number of stations with significant trends in precipitation occurred in winter while no significant trends were detected in summer precipitation. No decreasing significant trends were detected by statistical tests in annual and seasonal precipitation series. Therefore, it can be inferred that, no significant change in precipitation is observed during 1950-2007 in the study area.

Observed temperature tendencies indicated positive change in temperature, particularly in summer and spring over most of the stations. Moreover, temperature increment in winter is less in comparison with other seasons. Increasing tendencies in TMIN were more than TMAX in all the seasons. Therefore, the increase in annual and seasonal 


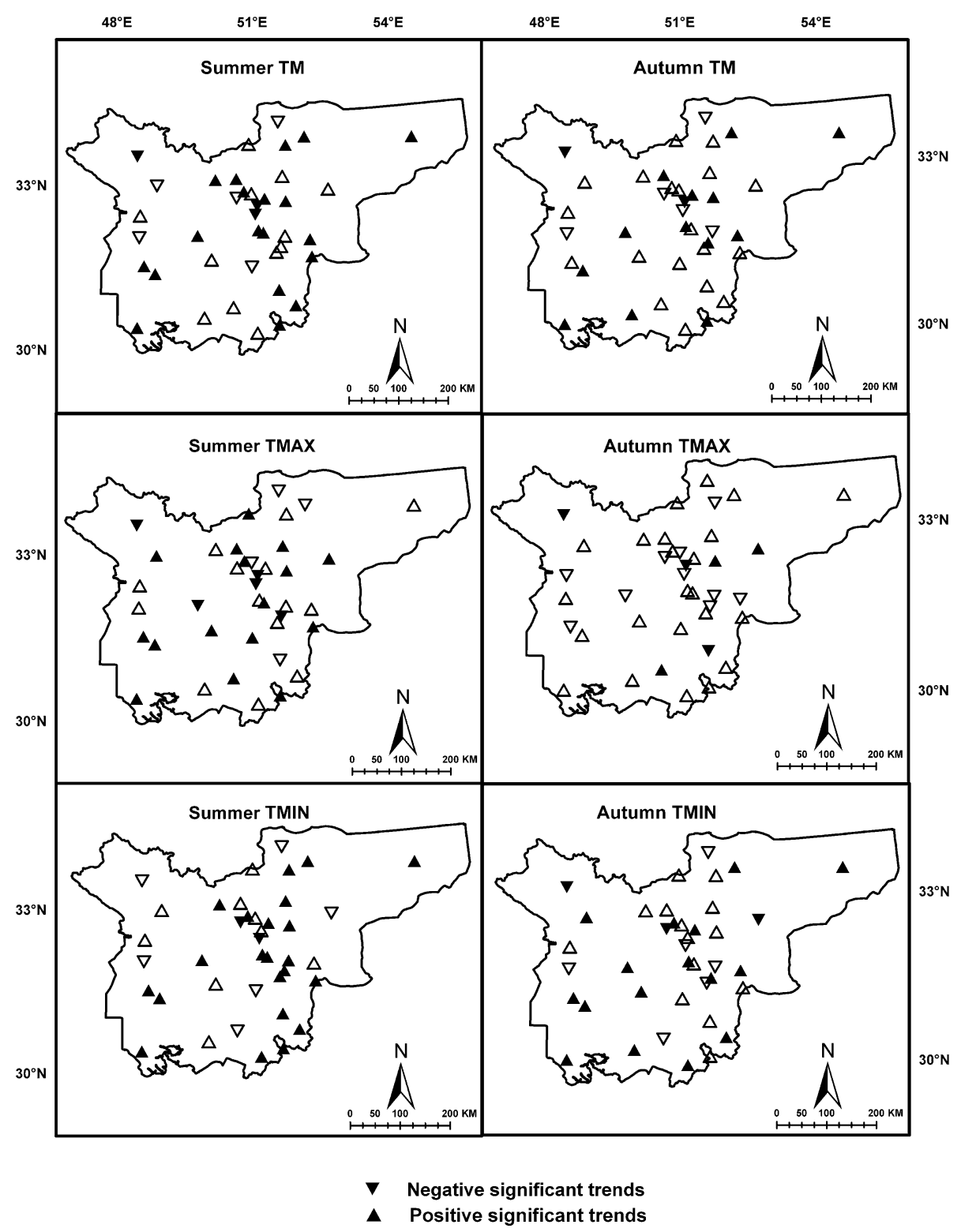

Figure 11. Trends detected by MK-test in TM, TMAX and TMIN of summer and autumn series. Significant trends at $95 \%$ confidence level are indicated by shaded triangles and hollow triangles indicate insignificant trends.

TM can be attributed to higher increase in TMIN. The results showed that most of the positive significant mutation points began in 1990s in the study area. Strong warming trends were detected at the stations near large cities in the study area. Population growth, urbanization, and industrialization during the last 30 years could be some of the reasons for warming trend in temperature. With no significant change in precipitation, and significant increasing trends in temperature, particularly during summer and spring, will lead to increase in evaporation rates during these seasons. This may lead to increased aridity during these seasons and will put more pressure on surface and ground water resources in the study area.
The results also suggest further investigations, to examine other meteorological series available in the Middle East which could be useful in knowing the effect of the climate change in the study area.

\section{Acknowledgements}

The authors are thankful to the Islamic Republic of Iran Meteorological Organization (IRIMO) and Water Resources Management Organization of the Ministry of Energy Islamic Republic of Iran for providing observed data. The authors are also grateful to anonymous reviewers whose suggestions have helped to improve the quality of this paper. 


\section{References}

Al Buhairi M H 2010 Analysis of monthly, seasonal and annual air temperature variability and trends in Taiz city - Republic of Yemen; J. Environ. Protection 1 401-409.

Alexandersson H A 1986 A homogeneity test applied to precipitation data; Int. J. Climatol. 6 661-675.

Alexandersson H and Moberg A 1997 Homogenization of Swedish temperature data. Part I: Homogeneity test for linear trends; Int. J. Climatol. 17 25-34.

Alijani B 1997 Some statistical characteristics of temperature variations in Iran; J. Res. Geogr. $3124-33$.

Boroujerdy P S 2008 The analysis of precipitation variation and quantiles in Iran, 3rd IASME/WSEAS; Int. Conf. on Energy \& Environment, University of Cambridge, UK, February 23-25.

Croitoru A E, Holobaca I H, Catalin Lazar C, Moldovan F and Imbroane A 2012 Air temperature trend and the impact on winter wheat phenology in Romania; Clim. Change 111(2) 393-410.

Dhorde A G and Zarenistanak M 2013 Three-way approach to test data homogeneity: An analysis of temperature and precipitation series over southwestern Islamic Republic of Iran; J. Indian Geophys. Union 17(3) 233-242.

Dhorde A, Dhorde A and Gadgil A 2009 Long-term temperature trends at four largest cities of India during the twentieth century; J. Indian Geophys. Union 13(2) 85-97.

Gadgil A and Dhorde A 2005 Temperature trends in twentieth century at Pune, India; Atmos. Environ. 39 6550-6556.

Ghahraman B and Taghvaeian S 2008 Investigation of annual rainfall trends in Iran;; J. Agri. Sci. Tech. 10 93-97.

IPCC 2007 Summary for policymakers; In: Climate change 2007: The physical science basis (eds) Solomon S, Qin D, Manning M, Chen Z, Marquis M, Averyt K B, Tignor M and Miller H L, Contribution of Working Group I to the Fourth Assessment Report of the Intergovernmental Panel on Climate Change; Cambridge University Press.

Kang H M and Yusof F 2012 Homogeneity tests on daily rainfall series in peninsular Malaysia; Int. J. Contemp. Math. Sci. 7(1) 9-22.

Karpouzos D K, Kavalieratou S and Babajimopoulos C 2010 Trend analysis of precipitation data in Pieria Region (Greece); European Water 30 31-40.

Katiraie P, Hajjam H and Irannejad P 2007 Contribution from the variations of precipitation frequency and daily intensity to the precipitation trend in Iran over the period 1960-2001; J. Earth Space Phys. 33(1) 22.

Lu A, He Y, Zhang Z, Pang H and Gu J 2004 Regional structure of global warming across China during the twentieth century; Clim. Res. 27 189-195.

Modarres R and da Silva V 2007 Rainfall trends in arid and semi-arid regions of Iran; J. Arid Environ. 70 344-355.

Mosmann V, Castro A, Fraile R, Dessens J and Sanches J L 2004 Detection of statistically significant trends in the summer precipitation of mainland Spain; Atmos. Res. $7043-53$.

Partal T and Kahya E 2006 Trend analysis in Turkish precipitation data; Hydrol. Process. 20 2011-2026.

Pettitt A N 1979 A non-parametric approach to the change point problem; J. Appl. Statist. 28(2) 126-135.

Raziei T 2008 Investigation of annual precipitation trends in homogeneous precipitation sub-divisions of western Iran; BALWOIS 2008 - Ohrid, Republic of Macedonia, 27-31 May 2008.
Roshan G H, Khoshakh Lagh F, Azizi G and Mohammadi H 2011 Simulation of temperature changes in Iran under the atmosphere carbon dioxide duplication condition; Iran J. Environ. Health Sci. Eng. 8 139-152.

Sabohi R 2009 Trend analysis of climatic factors in great cities of Iran; Int. J. Climate Change 18 34-43.

Serra C, Burgueno A and Lana X 2001 Analysis of maximum and minimum daily temperatures recorded at Fabra Observatory (Barcelona, NE Spain) in the period 1917-1998; Int. J. Climatol. 21 617-636.

Shifteh Some/e B, Ezani A and Tabari H 2012 Spatiotemporal trends and change point of precipitation in Iran; Atmos. Res. 113 1-12.

Shirgholami H and Ghahraman B 2009 Study of time trend changes in annual mean temperature of Iran; J. Sci. Tech. Agri. Nat. Res. 23 44-53.

Smadi M M 2006 Observed abrupt changes in minimum and maximum temperatures in Jordan in the 20th century; Am. J. Environ. Sci. 2(3) 114-120.

Smadi M M and Zghoul A 2006 A sudden change in rainfall characteristics in Amman, Jordan during the mid 1950's; Am. J. Environ. Sci. 2(3) 84-91.

Sneyers S 1990 On the statistical analysis of series of observations; Technical note no. 143, WMO No. 725 415, Secretariat of the World Meteorological Organization, Geneva, $192 \mathrm{p}$.

Sun H, Chen Y, Li W, Li F, Chen Y, Hao X and Yang Y 2010 Variation and abrupt change of climate in Ili River Basin, Xinjiang; J. Geogr. Sci. 20(5) 652-666.

Tabari H and Hosseinzadeh Talaee P 2011a Shift changes and monotonic trends in autocorrelated temperature series over Iran; Theor. Appl. Climatol. 109(1-2) 95-108.

Tabari H and Hosseinzadeh Talaee P 2011b Temporal variability of precipitation over Iran: 1966-2005; J. Hydrol. 396(3-4) 313-320.

Tabari H and Hosseinzadeh Talaee P 2011c Recent trends of mean maximum and minimum air temperatures in the western half of Iran; Meteor. Atmos. Phys. 111 121-131.

Tabari H and Hosseinzadeh Talaee P 2011d Analysis of trends in temperature data in arid and semi arid-regions of Iran; J. Global Planet. Change 79 1-10.

Tabari H and Marofi S 2011 Changes of pan evaporation in the west of Iran; Water Resourc. Manag. 25 97-111.

Tabari H, Marofi S and Ahmadi M 2010 Long-term variations of water quality parameters in the Maroon River, Iran; Environ. Monit. Assess. 177 273-287.

Tabari H, Some/e B S and Zadeh M R 2011 Testing for longterm trends in climatic variables in Iran; Atmos. Res. 100 $132-140$.

Tarhule A and Woo M 1998 Changes in rainfall characteristics in northern Nigeria; Int. J. Climatol. 18 1261-1271.

Turkes M and Sumer U M 2004 Spatial and temporal patterns of trends and variability in diurnal temperature ranges of Turkey; Theor. Appl. Climatol. 77 195-227.

Wijngaard J B, Klein Tank M and Konnen G P 2003 Homogeneity of 20th century European daily temperature and precipitation series; Int. J. Climatol. 23 679-692.

Yue S and Hashino M 2003 Long term trends of annual and monthly precipitation in Japan; J. Am. Water. Resour. 39(3) 587-596.

Zer Lin W, Chung Tsai H, Ho Wang C and Hsien Teng W 2005 Urbanization-induced regional climate change on the western plain of Taiwan for the period 1964 1999; Int. Conf. on Environment, Ecosystems and Development, Venice, Italy, November 2-4, 2005. 